\title{
Spatial Time Dependent Reliability Analysis of Carbonation with Climate Change
}

\author{
S.P. Murali Kannan ${ }^{1 *}$, K. Sudalaimani² \\ ${ }^{1}$ Department of Civil Engineering, Kamaraj College of Engineering and Technology, Madurai, India \\ ${ }^{2}$ Department of Civil Engineering, Thiagarajar College of Engineering, Madurai, India
}

Received: 19 February 2020

Accepted: 16 March 2020

\begin{abstract}
The ambiance around the concrete structures could be affected by a dynamic climate, particularly after a long time, results in declination of durability at a quicker rate. The increase in carbon dioxide concentration and temperature can increase the carbonation depth of concrete. Carbonation-induced corrosion of concrete structures in Bern and Seoul under a dynamic climate is investigated during this work by considering high and medium greenhouse gas emissions scenarios RCP 8.5 and RCP 4.5 respectively. This analysis takes into account the effect of change in temperature, carbon dioxide levels and relative humidity on diffusion coefficients considering relative humidity as a time-dependent variable. This work also evaluates the failure probability of durability based on the reliability concept by considering the coefficient of variation of carbonation depth and cover depth. Reliability index of 1.28 which infers the probability of corrosion initiation less than $10 \%$ is used for inference.
\end{abstract}

Keywords: corrosion, climate change, exploratory spatial data analysis

\section{Introduction}

Reinforced concrete is extensively used in the construction of buildings as it is comparatively cheap and provides large durability. Durability gets reduced drastically by corrosion when the reinforced concrete structures are situated in environments with high $\mathrm{CO}_{2}$ concentrations. Carbonation is induced when the atmospheric carbon dioxide reacts with cement hydrates and forming calcite. This chemical reaction significantly decreases the $\mathrm{pH}$ in the porous solution and thus it induces corrosion of the reinforcing steel. Parameters governing carbonation depend on temperature,

*e-mail: spm.kcet@gmail.com atmospheric carbon dioxide concentration and relative humidity, all related with time and climate change [1].

Study on the influence of climate change on the durability of concrete structures using statistical regression analysis of a number of pertinent experimental and field data resulted that temperature, concentration of $\mathrm{CO}_{2}$, and relative humidity play a vital role in the concrete carbonation rates [2]. Park et al presented a probabilistic approach to predict the service life of concrete structures subjected to carbonation based on the climate scenario IS92a which considered natural logarithm of time in prediction of $\mathrm{CO}_{2}$ concentration from the year 2000 to 2100 and linear variation in the prediction of temperature based on meteorological data from Korea Meteorological Administration [3].

Yoon et al. developed a durability model considering the effect of increase in the concentration of $\mathrm{CO}_{2}$ on 
the carbonation of concrete with respect to watercement ratio [4]. Joeri Rogelj et al estimated increase in carbon dioxide concentration to $936 \mathrm{ppm}$ and increase in temperature of $4 \cdot 0-6 \cdot 1^{\circ} \mathrm{C}$ by 2100 [5]. Deterministic models for predicting carbonations depths were proposed considering the increase in carbon dioxide concentration, temperature while ignoring the effect of change in relative humidity $[6,7,8]$. The objective of this work is to include the effect of relative humidity in employing spatial time-dependent reliability analysis for carbonation depth prediction.

In approximate moment approach, Byeng Youn et al. performed FORM by approximating the performance function using the first-order Taylor series expansion at the design point [9]. Cheng et al. proposed the concept of sequential approximate programming and applied Taylor linear approximation to both design variables and random variables [10]. Roudak et al. compared the results of generalization of HL-RF method with firstorder terms of Taylor approximation in computing reliability index [11]. Zhangli $\mathrm{Hu}$ et al. examined the accuracy of saddle point approximation in reliability analysis incorporating first-order Taylor expansion [12]. Yongsu Jung et al. employed first-order terms of Taylor approximation in FORM and compared the results with approximated dimension reduction methods [13]. This study also examines the initiation probability of steel corrosion based on the reliability concept incorporating first-order Taylor series expansion for reinforced concrete structures in the Switzerland city of Bern and the Chinese city of Seoul as case studies in this work.

\section{Materials and Methods}

For research activities, Intergovernmental Panel on Climate Change offered the change in climate scenario as open-source software. The four representative concentration pathways, - RCP 2.6, RCP 4.5, RCP

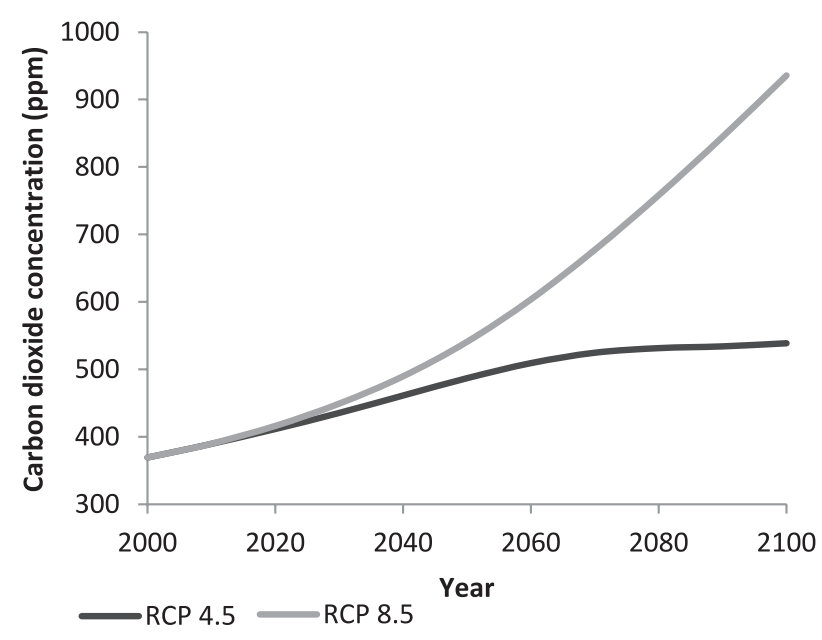

Fig. 1. Predicted global annual average carbon dioxide concentration for RCP 8.5, RCP 4.5 emissions.
6.0 and RCP 8.5 -named based on the predicted radiative forcing values in the year $2100(2.6,4.5,6.0$ and $8.5 \mathrm{~W} / \mathrm{m}^{2}$ respectively) were reported in IPCC fifth assessment report [14]. Fig. 1 shows the projection of annual average carbon dioxide concentration for RCP 4.5 and RCP 8.5 from the year 2000 [10-12].

Four climate models were chosen for the present study namely CanESM2 from Canadian Centre for Climate Modelling and Analysis, Canada, ACCESS1.0 from Commonwealth Scientific and Industrial Research Organisation, Australia, CSIRO-Mk3-6-0 from Commonwealth Scientific and Industrial Research Organization in collaboration with the Queensland Climate Change Centre of Excellence, Australia, MIROC5 from Atmosphere and Ocean Research Institute (The University of Tokyo), National Institute for Environmental Studies and Japan Agency for Marine-Earth Science and Technology were accessed freely from https://esgf-node.llnl.gov/projects/esgf$1 \operatorname{lnl} /$ and only one ensemble member (rlilp1) run has been used (similar to $[18,19])$. The output from the four models was downloaded as NetCDF files and converted to Excel file using $\mathrm{R}$ software [15, 16, 17]. The results were employed for temperature and relative humidity prediction from 2010 to 2100 corresponding to RCP8.5, and RCP4.5 for the cities Bern and Seoul (whose corresponding latitude and longitude values $46.94809,7.44744,37.566,126.9784)$, are shown in Fig. $2-$ a) to d) respectively.

Taking into account carbonation process as a steady-state process modelled by Fick's first law, where carbon dioxide concentration, temperature and relative humidity are time-dependent, the carbonation depth model can be written as:

$$
\begin{gathered}
x_{c}(t)=\left[\frac{2 D(t)}{a} \int_{2010}^{t} f_{T}(t) f_{R H}(t) k_{\text {site }} C_{C O 2}(t) d t\right]^{0.5} \\
*\left(\frac{t_{0}}{t-2009}\right)^{n_{m}} \\
D(t)=D_{1}(t-2009)^{-n_{d}} \\
a=0.75 C_{e} C_{C a O} a_{H} \frac{M_{C O 2}}{M_{C a O}} \\
a_{H}=1-e^{-3.38 * w / c}
\end{gathered}
$$

...where $\mathrm{t}$ is in years starting from 2010, $x_{c}(t)$ denotes the carbonation depth at time $\mathrm{t}, \mathrm{C}_{\mathrm{CO} 2}(t)$ denotes the increase in atmospheric carbon dioxide concentration with respect to time $\left(10^{-3} \mathrm{~kg} / \mathrm{m}^{3}\right)$ as shown in Fig. 1 (using the conversion factor $\left.1 \mathrm{ppm}=0.0019 * 10^{-3} \mathrm{~kg} / \mathrm{m}^{3}\right)$. The significance of temperature on diffusion coefficient is modelled as per the Arrhenius law (similar to [4]), where the time-dependent change in diffusion coefficient when compared to a temperature of $20^{\circ} \mathrm{C}$ is 


$$
f_{T}(t)=\exp \left\{\frac{E}{R}\left[\frac{1}{293.15}-\frac{1}{273.15+T(t)}\right]\right\}
$$

in which $T(t)$ is the temperature $\left({ }^{\circ} \mathrm{C}\right)$ at time $\mathrm{t}, \mathrm{E}$ is the activation energy of the diffusion process $(40 \mathrm{~kJ} / \mathrm{mol}$ ([23]) and $\mathrm{R}$ is the gas constant $\left(8.314 * 10^{-3} \mathrm{~kJ} / \mathrm{mol} \mathrm{K}\right)$. The Model Code for Service Life Design (fib, 2006) recommends a model to consider the influence of $\mathrm{RH}$ on the diffusion coefficient

a)

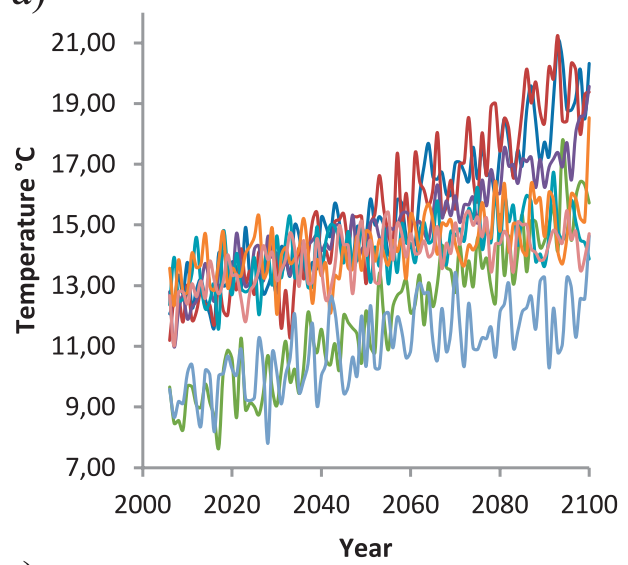

c)

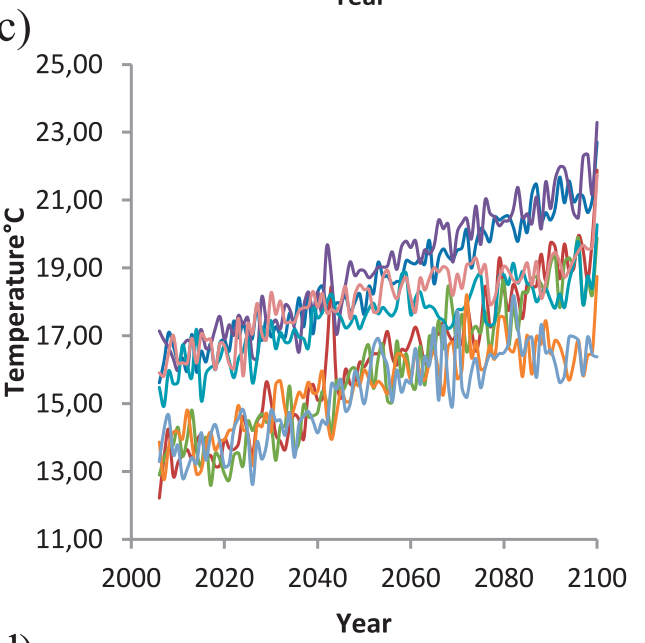

d)

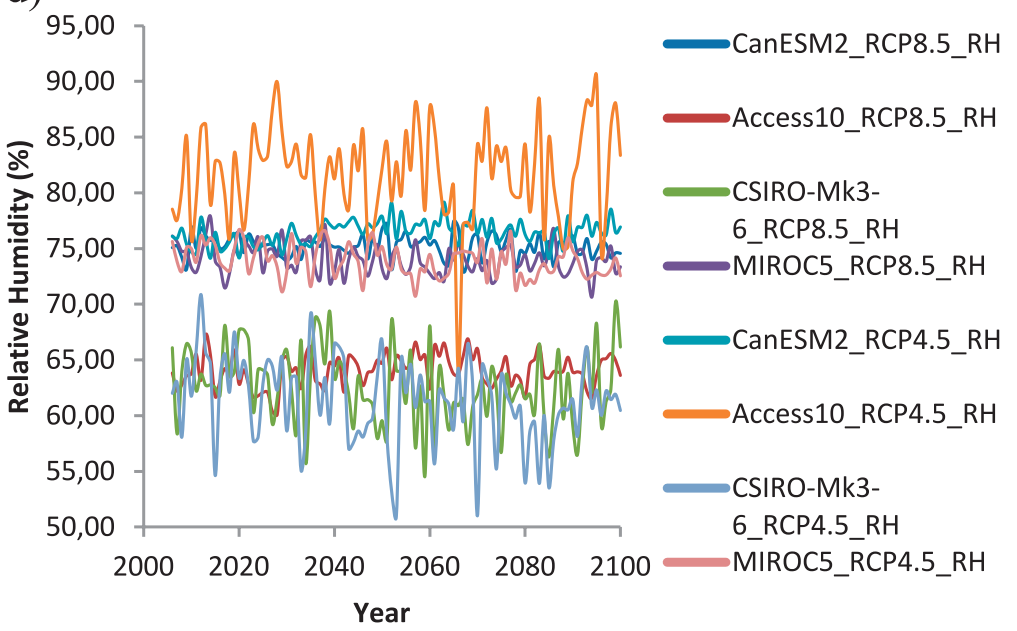

$$
f_{R H}(t)=\left[\frac{1-(R H(t) / 100)^{f_{e}}}{1-\left(R H_{r e f} / 100\right)^{f_{e}}}\right]^{g_{e}}
$$

...where $\mathrm{RH}_{\text {ref }}$ is the reference $\mathrm{RH}(=65 \%$ at temperature $\left.=20^{\circ} \mathrm{C}\right), f_{e}$ is a constant $(=5.0)$ and $g_{e}$ is a constant $(=2.5)$. Carbonation have a tendency to be highest for relative humidity $\mathrm{RH}(\mathrm{t})=50-70 \% \quad$ ([24]). The values of $\mathrm{T}(\mathrm{t})$ and $\mathrm{RH}(\mathrm{t})$ were taken from the

b)

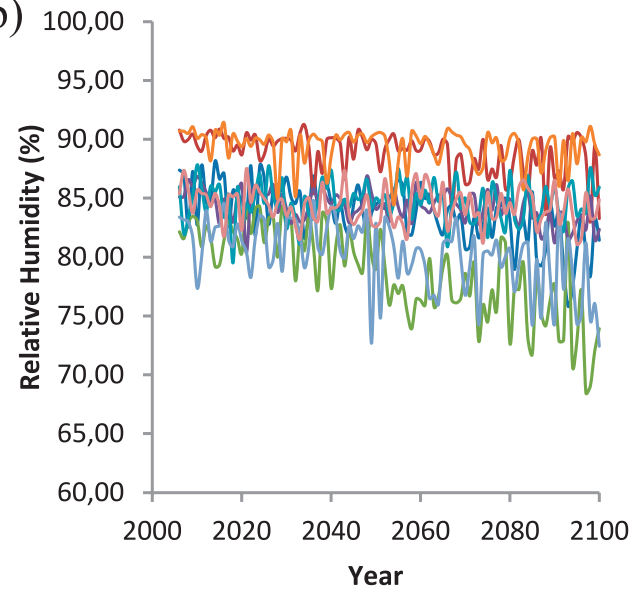

CanESM2_RCP8.5

Access10_RCP8.5

CSIRO-Mk3-6_RCP8.5

MIROC5_RCP8.5

$\longrightarrow$ CanESM2_RCP4.5

Access10_RCP4.5

CSIRO-Mk3-6_RCP4.5

MIROC5_RCP4.5

Fig. 2. a) Temperature Prediction - RCP 8.5 \& RCP 4.5 - Bern, b) Relative Humidity Prediction - RCP 8.5 \& RCP 4.5 - Bern, c) Temperature Prediction - RCP 8.5 \& RCP 4.5 - Seoul, d) Relative Humidity Prediction - RCP 8.5 \& RCP 4.5 - Seoul. 
Table 1. Mean parameter values [4].

\begin{tabular}{|c|c|c|}
\hline w/c ratio & $\mathrm{D} 1: 10^{-4} \mathrm{~cm}^{2} / \mathrm{s}$ & $n_{d}$ \\
\hline 0.45 & 0.65 & 0.218 \\
\hline 0.5 & 1.24 & 0.235 \\
\hline 0.55 & 2.22 & 0.240 \\
\hline
\end{tabular}

climate model CSIRO-Mk3-6-0. $k_{\text {site }}$ is a factor to account for increased carbon dioxide levels in nonremote environments, $D(t)$ is the carbon dioxide diffusion coefficient in concrete calibrated for 2010 to $2100, \mathrm{D} 1$ is the carbon dioxide diffusion coefficient at $\mathrm{t}=2010, n_{d}$ is the age factor for the carbon dioxide diffusion coefficient, $t_{0}$ is 1 year, $C_{e}$ is the cement content $\left(\mathrm{kg} / \mathrm{m}^{3}\right), C_{\mathrm{CaO}}$ is the calcium oxide content in cement (0.65), $a_{H}$ is the degree of hydration, $M_{C a O}$ is the molar
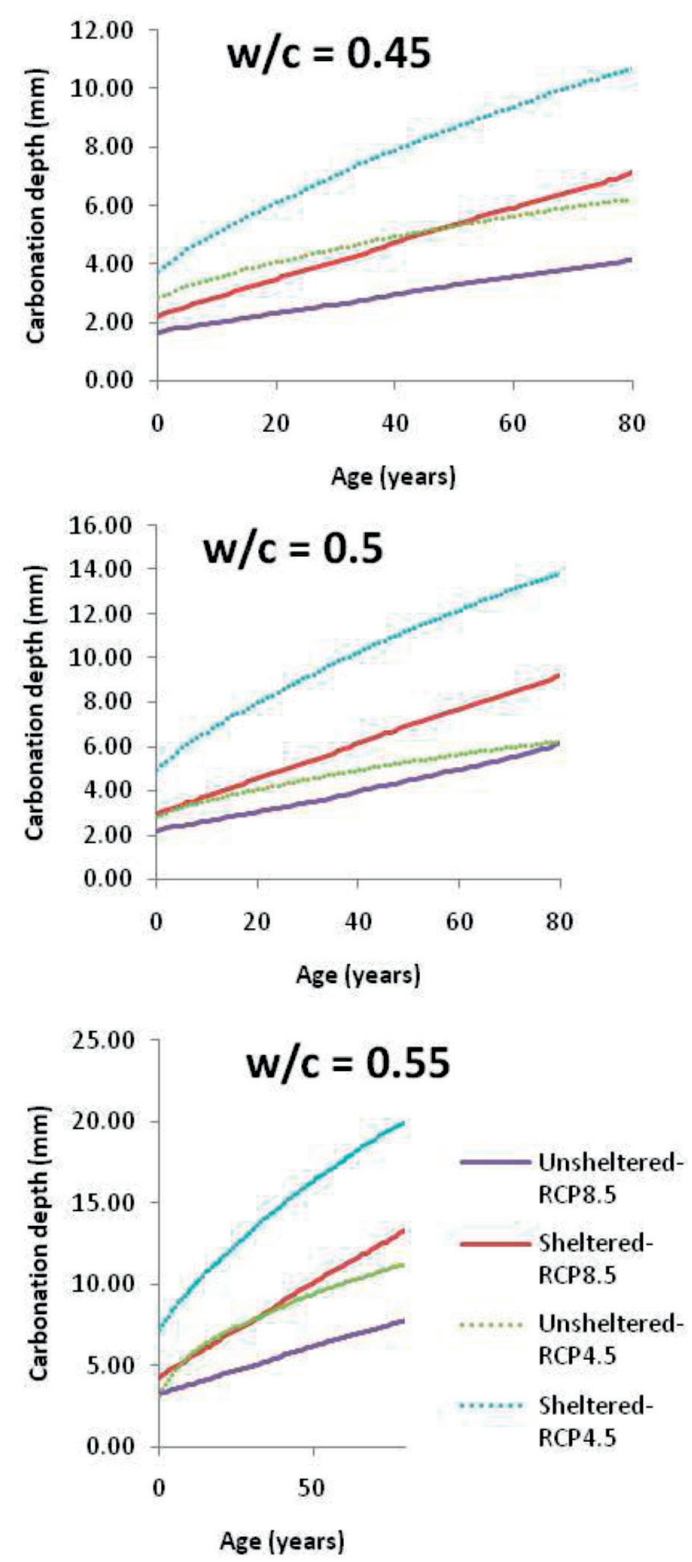

mass of calcium oxide ( $=56 \mathrm{~g} / \mathrm{mol}), M_{\mathrm{CO} 2}$ is the molar mass of carbon dioxide $(=44 \mathrm{~g} / \mathrm{mol})$ and w/c is the water/cement ratio[4]. The age factor $n_{m}$ related with the occurrence of wetting and drying cycles is $n_{m}=0$ for sheltered outdoor exposure and $n_{m}=0.12$ for unsheltered outdoor exposure.

Carbon dioxide level in urban area will be generally higher than the global mean value measured at remote areas like Mauna Loa in Hawaii because of anthropogenic and natural sources, correction factor $k_{\text {site }}$ values of $1,14,1.07,1.05$ were used respectively to urban, sub-urban and rural area to convert global mean $\mathrm{CO}_{2}$ concentration to respective local levels. Table 1 represents the mean values for $\mathrm{D} 1$ and $n_{d}$ as a function of $\mathrm{w} / \mathrm{c}$ ratio [4]. The mean carbonation depths of sheltered and unsheltered structures in Bern and Seoul are shown in Fig. 3a) and b) respectively.
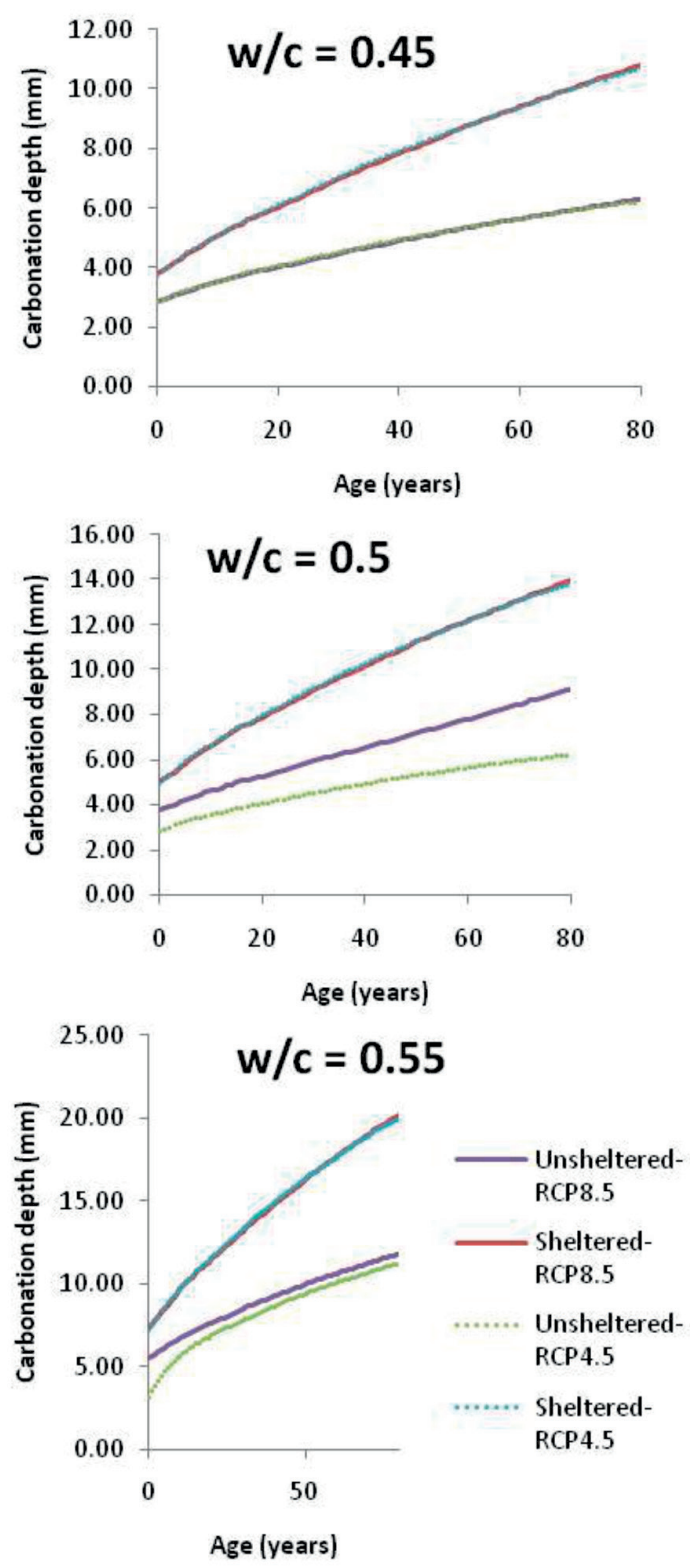

Fig. 3. Mean Carbonation depth for various a) w/c ratio - Bern, b) w/c ratio - Seoul. 


\section{Results and Discussion on Reliability Concept}

The basic reliability problem considers one load effect $\mathrm{Q}$ resisted by one resistance $\mathrm{R}$ which must be expressed in same units [25]. The probability of failure, $\left(\mathrm{P}_{f}\right)$ of the structural element can be stated as:

$$
P_{f}=P(R \leq Q)=P(R-Q \leq 0)
$$
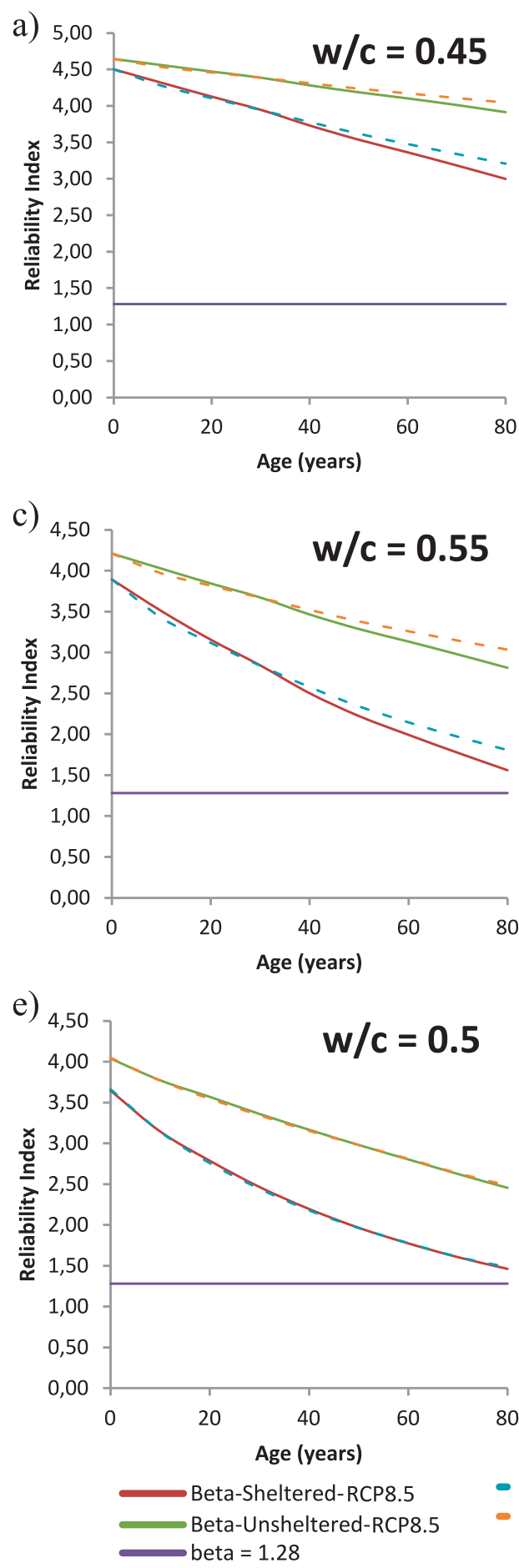

80

Beta-Sheltered-RCP4.5
Beta-Unsheltered-RCP4

d)
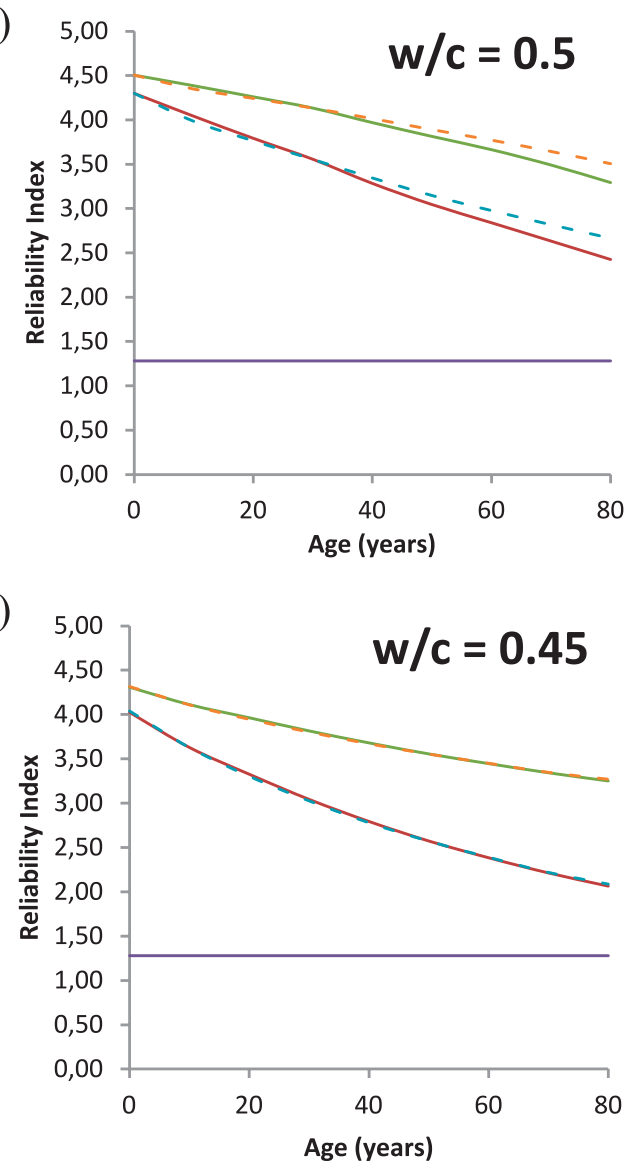

f)

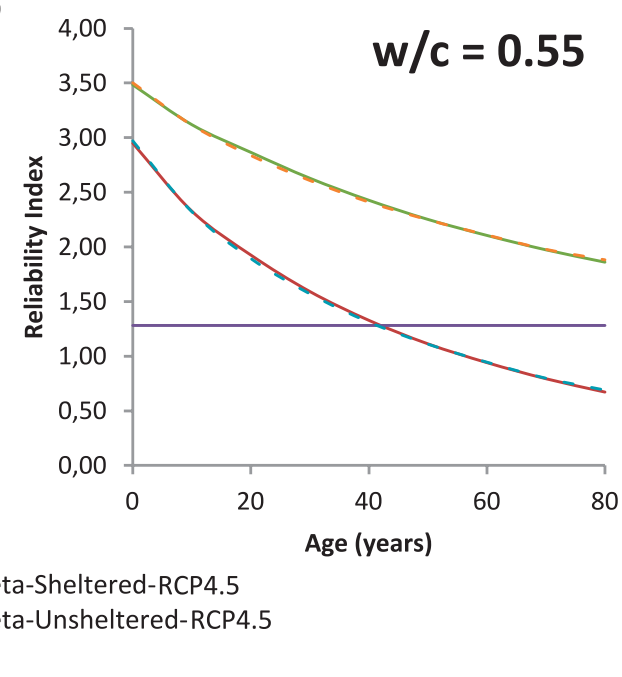

Fig. 4. Reliability index of durability failure by carbonation for w/c ratio of: a) 0.45 - Bern, b) 0.5 - Bern, c) 0.55 - Bern, d) 0.45 - Seoul, e) 0.5-Seoul, f) 0.55- Seoul. 
...where $\mu$ and $\sigma$ are the statistical parameters, mean and standard deviation. In first-order second moment (FOSM) method incorporating first-order Taylor series approximation, Reliability index can be interrelated to probability of failure by the following formula:

$$
P_{f}=\Phi\left(-\frac{\mu_{z}}{\sigma_{z}}\right)=\Phi(-\beta)
$$

...where $\mu_{z}$ is mean of limit state equation, $\sigma_{z}$ is standard deviation of limit state equation, $\beta$ is reliability index and $\Phi$ is standard normal distribution function [27, 28]. This study implements coefficient of variation for carbonation depth as $15 \%$ as well as cover depth as $20 \%$ in this analysis to reflect on the large variation of carbonation depth in performing durability design $[3,29]$.

$$
\begin{gathered}
\mu_{z}=\mu_{c}-\mu_{d} \\
\sigma_{z}=\sqrt{\sigma_{c}^{2}+\sigma_{d}^{2}}=\sqrt{\left(\left(0.2 \mu_{c}\right)^{\wedge} 2\right)+\left(\left(0.15 \mu_{d}\right)^{\wedge} 2\right)}
\end{gathered}
$$

...where $\mu_{c}, \sigma_{c}$ are mean of cover depth $(30 \mathrm{~mm})$ and standard deviation of cover depth, $\mu_{d}, \sigma_{d}$ are mean and standard deviation of carbonation depth with respect to age of structure varying from 0 to 100 years. Reliability index is computed for Bern, Seoul at RCP 8.5 and RCP 4.5 climate scenarios in Fig. 4(a-f).

Corrosion gets started once the probability of corrosion initiation exceeds $10 \%$ which corresponds to reliability index of 1.28 [30]. Using standard cumulative function, time to reach $10 \%$ probability of corrosion initiation can be computed. From the time to reach $10 \%$ probability of corrosion initiation repair and maintenance works can be foreseen based on the w/c ratio of the structure in Bern and Seoul environmental condition [31]. Computing reliability index using mean, standard deviation, coefficient of variation and from there on computation of probability of corrosion initiation can be helpful in foreseeing strategic maintenance works if any. Reliability index assessment can be useful in decision making about alternatives or maintenance planning [28]. Such reliability computations by accounting randomness and uncertainties should be employed in assessment of target reliabilities in the classification of performance based design [32].

\section{Conclusions}

This paper has illustrated a spatial time-dependent reliability analysis of the carbonation-induced corrosion under a dynamic climate by including coefficient of variation of concrete cover and carbonation depth. Timedependent carbon dioxide concentration, temperature, relative humidity effects on carbonation depth extracted from a CMIP5 climate model is included in the carbonation depth model. The results from the spatial time-dependent reliability analysis were presented in terms of reliability index for locations in Switzerland and Korea which indirectly infers the time for proposed maintenance activities.

For the worst-case scenario, the time of the first repair could occur as soon as 2060 and 2065 for sheltered structures for the water-cement ratio of 0.55 in Seoul, South Korea considering the climate change. Future construction of structures should ensure adequate concrete cover, improved quality of concrete, and the provision of surface coatings to inhibit carbon dioxide ingress to take into account degradation due to climate change when they are being designed. The analysis conducted in this study indicates that the risk of corrosion in reinforced concrete structures in Bern, Switzerland by carbonation will be very small as the predicted relative humidity of the city is not within the range between $50 \%$ and $70 \%$. The presented findings could help us in foreseeing the cost-effective decisionmaking process concerning the maintenance planning for structures based on w/c ratios in the concerned locations of the world.

\section{Data Availability}

The data used to support the findings of this study are available from the corresponding author upon request.

\section{Conflicts of Interest}

All the authors declare that they have no conflicts of interest.

\section{Funding Statement}

The author(s) received no financial support for the research and publication of this article.

\section{Acknowledgements}

The author acknowledges the support from the Kamaraj College of Engineering \& Technology, Virudhunagar and Thiagarajar College of Engineering, Madurai, Tamil Nadu, India to complete the work successfully

\section{References}

1. DE LARRARD T., BASTIDAS-ARTEAGA E., DUPRAT F., SCHOEFS F. Effects of climate variations and global warming on the durability of RC structures subjected to carbonation. Civil Engineering and Environmental Systems, 31 (2), 153, 2014. 
2. KAEWUNRUEN S. Vulnerability of Structural Concrete to Extreme Climate Variances. MDPI, 1, 2018.

3. PARK K.B., WANG X.Y. Effect of climate change on service life of high volume fly ash concrete subjected to carbonation-a Korean case study. Sustainability (Switzerland), 9 (1), 2017.

4. YOON I.S., ÇOPUROĞLU O., PARK K.B. Effect of global climatic change on carbonation progress of concrete. Atmospheric Environment, 41 (34), 7274, 2007.

5. ROGELJ J., MEINSHAUSEN M., KNUTTI R. Global warming under old and new scenarios using IPCC climate sensitivity range estimates. Nature Climate Change, 2 (4), 248, 2012.

6. STEWART M.G., WANG X., NGUYEN M.N. Climate change impact and risks of concrete infrastructure deterioration. Engineering Structures, 33 (4), 1326, 2011.

7. TALUKDAR S., BANTHIA N., GRACE J.R. Carbonation in concrete infrastructure in the context of global climate change - Part 1: Experimental results and model development. Cement and Concrete Composites, 34 (8), 924, 2012.

8. TALUKDAR S., BANTHIA N., GRACE J.R., COHEN S. Carbonation in concrete infrastructure in the context of global climate change: Part 2 - Canadian urban simulations. Cement and Concrete Composites, 34 (8), 931, 2012.

9. YOUN B.D., CHOI K.K. Selecting Probabilistic Approaches for Reliability-Based Design Optimization. AIAA Journal, 42 (1), 124, 2004.

10. CHENG G., XU L., JIANG L. A sequential approximate programming strategy for reliability-based structural optimization. Computers \& Structures, 84 (21), 1353, 2006.

11. ROUDAK M.A., SHAYANFAR M.A., BARKHORDARI M.A., KARAMLOO M. A robust approximation method for nonlinear cases of structural reliability analysis. International Journal of Mechanical Sciences, 133, 11, 2017.

12. HU Z., DU X. Reliability Methods for Bimodal Distribution With First-Order Approximation1. ASCEASME J Risk and Uncert in Engrg Sys Part B Mech Engrg, 5 (1), 2019.

13. JUNG Y., CHO H., LEE I. MPP-based approximated DRM (ADRM) using simplified bivariate approximation with linear regression. Structural and Multidisciplinary Optimization, 59 (5), 1761, 2019.

14. INMAN M. Opening the future. Nature Publishing Group, 1 (1), 7, 2011.)

15. CLARKE L.E., JACOBY H., PITCHER H., REILLY J., RICHELS R. Scenarios of Greenhouse Gas Emissions and Atmospheric. US Department of Engergy, (July), 154. (2007)

16. WISE M., CALVIN K., THOMSON A., CLARKE L., BOND-LAMBERTY B., SANDS R., EDMONDS J. Implications of limiting $\mathrm{CO}_{2}$ concentrations for land use and energy. Science, 324 (5931), 1183, 2009.

17. RIAHI K., GRÜBLER A., NAKICENOVIC N. Scenarios of long-term socio-economic and environmental development under climate stabilization. Technological Forecasting and Social Change, 74 (7), 887, 2007.

18. SHARMILA S., JOSEPH S., SAHAI A.K., ABHILASH S., CHATTOPADHYAY R. Future projection of Indian summer monsoon variability under climate change scenario: An assessment from CMIP5 climate models. Global and Planetary Change, 124, 62, 2015.

19. KITOH A., ENDO H., KRISHNA KUMAR K., CAVALCANTI I.F.A., GOSWAMI P., ZHOU T. Monsoons in a changing world: A regional perspective in a global context. Journal of Geophysical Research Atmospheres, 118 (8), 3053, 2013.

20. UDDAMERI V. Using $\mathrm{R}$ to read NetCDF Files Using $\mathrm{R}$ to read NetCDF Files, (September). 2017.

21. ANDERSON G.B., EASON C., BARNES E.A. Working with daily climate model output data in $\mathrm{R}$ and the futureheatwaves package. R Journal, 9 (1), 124, 2017.

22. DAVID P. Package 'ncdf4.' Retrieved from https://cran.rproject.org/web/packages/ncdf4/ncdf4.pdf, 2019.

23. PENG L., STEWART M.G. Spatial time-dependent reliability analysis of corrosion damage to RC structures with climate change. Magazine of Concrete Research, 66 (22), 1154, 2014.

24. RUSSELL D., BASHEER P.A.M., RANKIN G.I.B., LONG A.E. Effect of relative humidity and air permeability on prediction of the rate of carbonation of concrete. Proceedings of the Institution of Civil Engineers: Structures and Buildings, 146 (3), 319, 2001.

25. MELCHERS R.E., BECK A.T. Structural Reliability Analysis and Prediction Third Edition. Retrieved from http://www.wiley.com/go/permissions. 2018.

26. ZADEH H.J., NANNI A. Incorporating Expected LifeTime into Live Load Factor for RC Structures Using Reliability Analysis. Advances in Structural Engineering, 16 (5), 887, 2013.

27. LI Z., JIN Z., ZHAO T., WANG P., ZHAO L., XIONG C., KANG Y. Service life prediction of reinforced concrete in a sea-crossing railway bridge in Jiaozhou Bay: A case study. Applied Sciences (Switzerland), 9 (17), 2019.

28. TEPLÝ B. Interrelation among Service Life, Reliability Index, and Costs of Concrete Structures Subjected to Aggressive Exposure. Journal of Performance of Constructed Facilities. 2014.

29. HAN S.H., PARK W.S., YANG E.I. Evaluation of concrete durability due to carbonation in harbor concrete structures. Construction and Building Materials. 2013.

30. ZOU X., WANG Q., WU J. Reliability-based performance design optimization for seismic retrofit of reinforced concrete buildings with fiber-reinforced polymer composites. Advances in Structural Engineering, 21 (6), 838, 2018.

31. CHIU C.K., NOGUCHI T., KANEMATSU M. Optimal Maintenance Plan for RC Members by Minimizing Life-Cycle Cost Including Deterioration Risk Due to Carbonation. Journal of Advanced Concrete Technology, 6 (3), 469, 2008

32. BHATTACHARYA B. Risk and reliability in bridges. Innovative Bridge Design Handbook, 155, 2016. 